\title{
Theories on Peacebuilding and Social Change
}

\author{
Dinda Dinda \\ Faculty of Economics and Business, Brawijaya University, Indonesia \\ ria_ans.soc11@koyauniversity.org
}

\begin{abstract}
When pursuing social change, questions about what should be the first priority have been a longstanding matter of philosophical interest and debate. What is more important? Is it efforts that expand individual and personal capacities? Or, is it efforts seeking to redress systems and structures? Do we start with the world out there - focusing on the distribution of power and resources within and between societies - or the world within - aiming to develop awareness, growth, and commitment to change on a personal level? While various approaches to peacebuilding and social justice can be located along the full range of this spectrum, conversations about how to approach these endeavors in a complimentary, integrated way are fairly new. Consequently, tensions do exist around how to set priorities. For instance, those committed to promoting attitude change must contend increasingly with critical perspectives which prioritize and address the structural roots of social conflict. On the other hand, those that pursue strictly the structural roots at the heart of a conflict situation —often the tactics and goals of critical social movementsare at risk of polarizing and enflaming conflict in ways that do not easily lead to constructive resolution. In other words, the bridge building skills of the peacemaker are key to conflict transformation work. At the same time, bridge building skills devoid of a critical social justice perspective are arguably shallow at best.
\end{abstract}

Keyword: Peacebuilding; Social Change

\section{Introduction}

Since the 1960s the field of conflict resolution has grown parallel and in conjunction with the development of social movements (Kriesberg 2001, 410). From his experience as both a mediator and a non-violent activist, Quigley (2010) has written about the distinct differences between social justice activists and conflict resolution practitioners along with a tension that often exists between the two(Quigley, 2010).

Further examining the relationship between non-violent activism and mediation, John Paul Lederach builds on the work of Adam Curl. This analysis is based on three key assumptions. One, that the bases of social conflicts are generally rooted in some form of perceived inequality or power imbalance. Two, that awareness and knowledge of this asymmetry is often lacking within the society or societies in question. And finally, that in order to move a conflict in the direction of sustainable peace, awareness of the conflictin particular, an awareness of the legitimate needs and interests of all concerned-must increase. In this way, the progression from unpeaceful to peaceful relations can be charted as moving from latent to overt, 
often with confrontation as an intermediate step before sides engage in conflict resolution processes (13). From this view, activists work on behalf of those who are seeking social change. Their role, as Lederach puts it, "is aimed at erasing ignorance and raising awareness as to the nature of unequal relationships and the need for addressing and restoring equity, as seen, of course, from the view of those experiencing the injustices" (Haim, 1962).

Social change may refer to the notion of social progress or sociocultural evolution, the philosophical idea that society moves forward by evolutionary means. It may refer to a paradigmatic change in the socioeconomic structure, for instance a shift away from feudalism and towards capitalism.

Social Development refers to how people develop social and emotional skills across the lifespan, with particular attention to childhood and adolescence. Healthy social development allows us to form positive relationships with family, friends, teachers, and other people in our lives.

Accordingly, it may also refer to social revolution, such as the Socialist revolution presented in Marxism, or to other social movements, such as Women's suffrage or the Civil rights movement. Social change may be driven through cultural, religious, economic, scientific or technological force's.

While activism often pursues confrontation towards the goal of awakening complacency and mobilizing change agents, peacebuilders are working to reduce a sense of adversariness. At the same time, these peacemakers are often building on the work of activists who, through agitating social tensions, have cultivated an acute awareness of the issues at the base of the conflict.

\section{Discussion}

At the same time, an analysis of the itineraries for these delegations reveals that advocacy for the injustice experienced by Palestinians is a dominant theme of the project. Further in alignment with the goals of social justice activism, some of the project's activities - such as the hands-on rebuilding of demolished Palestinian homes - can be considered political in that they challenge contested Israeli policies. Given this contradictory feature of the project, it becomes a valuable site for examining the attitudes, assumptions and values reflected in contemporary - popular - peacemaking practices, particularly as they relate to the nexus of reconciliation, justice and coexistence. A key reason I was initially drawn to the Compassionate Listening Project was because I was curious about the ways this project seemed to be experimenting-either consciously or in an ad hoc, perhaps intuitive manner - with both the interior and exterior dimensions of conflict transformation. Importantly in this regard, the themes that emerge from this study are examined in light of emerging themes of inquiry and practice in the field. Bringing light to these themes, what follows here is a look at some of the core bodies of theory and research that have informed this inquiry, along with my observations about the emerging new directions in the field to which this study hopes to contribute(Devlin, 1992).

Since the end of the Cold War, the world of global politics has undergone a turbulent transformation. The breakdown of a bipolar system has unleashed a period of global disorder characterized by uncertainty (Rasmussen 1997, 24). The intensity, destructiveness and persistent nature of conflicts such as in the Middle East, the Balkans and Rwanda has influenced a shift in traditional thinking about diplomacy and peacemaking. Inter-communal conflicts inevitably involve issues that extend into the deeper social fabric of society, beyond the reaches and interests of the state. As a result, it has become widely accepted by many practitioners and theorists in the conflict resolution field that these conflicts can not be effectively addressed simply through the formulation and implementation of political agreements(Forsythe, 2009). 
This new paradigm, referred to in the International Relations field as Pluralism, acknowledges nonstate actors as important entities that cannot be ignored and embraces the need to respond to the full complexity of socio-political dynamics within societies (Viotti and Kauppi 1998). Various perspectives and frameworks have been outlined by different conflict resolution scholars. John Paul Lederach (1997), for instance, argues for an integrative, comprehensive approach to peacemaking that calls for leadership from top, middle to grassroots levels of society to address the respective and varied needs of affected populations (39). Similarly, Jay Rothman (1992) asserts that politics need to be better informed by the personal and social dimensions of culture, values, needs and experiences of parties in the conflict (Chang, 1996).

In his book, A Public Peace Process, Harold Saunders (1999) adds to the growing body of work that challenges the assumptions of Realist politics by asserting that non-state actors have an important role to play in the domain of international diplomacy and peacemaking. Contrary to traditional, top-down approaches, he asserts that, in the case of deep-rooted social conflicts, governments cannot make peace

Rothman is stressing the need for efforts that aim to create the social conditions for peace that will ensure the success of political agreements, once they are in place. While improved relations between the adversaries had made remarkable strides towards the goal of peace, relations within each adversary then emerged as the significant obstacle in sustaining progress in that direction. A problem that many agree persists today.

Several practitioners and scholars have developed overarching perspectives on the roles that citizens can play to help ensure prospects for peace. John Paul Lederach (1997), for one, offers a model that calls for leadership from top, middle to grassroots levels of society to address the respective and varied needs of affected populations. Lederach calls for an integrated, comprehensive approach and stresses how this "points toward the functional need for recognition, inclusion, and coordination across all levels and activities. Both Diamond and McDonald (1996) and William Ury (2000) have developed systemic frameworks that map the overall collective potential of private humanitarian agencies, human rights advocates, and individual NGOs. An overview of each of these approaches follows below. Diamond and McDonald (1996) view the web of activities, individuals, institutions and communities that are the sum of state and non-state actors as a living system of interrelated parts functioning together towards the common end of peace. The term Multi-Track Diplomacy was conceptualized by Diamond and McDonald to refer to the diversity of actors and activities that contribute to international peacemaking. Multi-Track Diplomacy — as compared with First Track, or official diplomacy - is an expansion of what has come to be known as Track-Two Diplomacy, unofficial actors performing "a range of supplemental or parallel functions to help improve relationships at various levels and among different individuals" (Rasmussen 1997, 43).

There is an old Irish saying that goes, "Is this a private fight, or can anyone get in?" In this increasingly interdependent world... we seem to be learning that there are no private fights because they affect us all....[T]he third side is the community itself taking responsibility for its own conflicts. It's the community forming what might be called a 'winning alliance' against violent conflict. It's the community learning to serve as a container for contention, a container within which conflict can be transformed from destructive ways like violence and war, into constructive ways like dialogue, negotiation, and democracy (Band, 1991).

From a Third Side perspective, the community includes any group or organization, official or unofficial, performing roles that serve to contain, resolve or prevent a conflict. Like a Multi-Track approach, a Third Side perspective places high value on how various sectors of society can step forward to perform these crucial roles. Yet, what is unique about a Third Side perspective is the way it includes and considers parties and entities who have a variety of relationships to the conflict. In this way the Third Side is made up of insiders (family, friends, and those who are the direct parties to the conflict) and outsiders (such as neighbors or other kinds of concerned bystanders). As such, the Third Side offers an important lens for 
understanding and defining the Compassionate Listening Project, which functions as both as insider and outsider to the Israeli-Palestinian conflict. The Third Side shares in common with other citizen peacemaking approaches, the idea that peacemaking is a set of processes that requires the engagement of every dimension of society. This view is in clear contrast to the reductionist, top-down approach of Power Politics, but is certainly consistent with the new conceptual domain of thinking about how peacebuilding is most effectively done in our world as it is today.

Offering a key source of inspiration to this inquiry are the variety of ways that a grass roots people's awakening is arguably becoming an evident fact of our world (Walker 1988, Korten 1990, Schell 2003, Loeb 2004). The assertions of diverse cultures, the struggles for justice and dignity, the alternative development movement, as well as the variety of social movements are just some of the features of this emerging new landscape. In this regard, I believe that Compassionate Listening Project has location, generally, in this emerging new landscape, at the same time that it has specific location in the domain of citizen peacemaking.

David Band (1990) champions the visions and strategies of citizen movements as a critical factor in our ability to build sustainable futures. As popular examples from development and international studies literature, these books offer glimpses into ongoing conversations noting the emergence of a global civic society along with its important implications (Band, 1991).

In the period between the Second World War and end of the Cold War there are many examples of citizens engaged in diplomatic activities on the level of state relations. Of significance are the activities of the Dartmouth Conference; the Pugwash meetings; the Quakers; the World Council of Churches; and, the International Committee of the Red Cross. In their book, Unofficial Diplomats, Berman and Johnson (1977) examine such activities, the contributions to diplomacy as well as some of the ways that these roles have been perceived from an official point of view. The Dartmouth Conferences, for instance, are a series of meetings that have taken place at irregular intervals since 1960. President Eisenhower originally suggested the meetings because he believed that private citizens could be a helpful step towards official negotiations (Stein, 1961).

During this period, countless groups of Americans traveled to the Soviet Union with a sense of responsibility and mission. Meeting with every stratum of Soviet society - from Politburo members to peasants - these groups believed that through the expansion of dialogue between the two countries at every level, they were laying the groundwork for peace between the two superpowers. As described more fully in the following chapter, the early roots of the Compassionate Listening Project lie here, in this arena and era of citizen diplomacy.

Perhaps the most defining feature of the disparate, interdisciplinary world of conflict transformation and peacebuilding is its underlying optimism about the nature of human nature. This view stands in sharp contrast to the common belief that the human propensity for violence is a natural phenomenon. Consistent with this assumption, in the traditional world of international diplomacy coercive power is considered to be a primary ingredient for determining the outcome of a conflict. In this regard, conflict itself is treated as something to eliminate, manage or avoid. Indeed, the Super Power strategies during the Cold War sought to avoid, or deter conflict precisely through a strategic buildup of coercive forces (Friedland, 2002).

While it is safe to assume some general agreement exists around this larger goal and purpose of conflict resolution work, differences around how to approach the development of our capacities to handle conflict constructively further characterizes the field. Offering a map to these differences, Michelle LeBaron (2002) describes what she sees as an evolution of approaches to handling conflict. Her topography of the field in this regard outlines three waves of theory and practice, each with its own assertions about the roots of conflict and its resulting approach. An overview of LeBaron's framework, along with a look at how this 
framework overlaps and intersects with other maps of the field is presented here as an analytic tool for giving location to the Compassionate Listening Project.

According to this map, the citizen diplomacy movement generally fits into the second wave of practices, otherwise termed a human relations approach, to resolving conflict. The first wave of practices addresses differences arising "from competition over resources and differences over material things". LeBaron emphasizes how analytical frameworks and logical, staged processes are the modus operandi of this approach. Providing a key example are the problem-solving approaches that separate the person from the issues, and where getting to "yes" becomes the key measure of success. In terms of the Israeli-Palestinian conflict, Herb Kelman's prominant and well-known problem solving workshops, for instance, have been credited with preparing the ground out of which the Oslo Accords were possible (Chang, 1996). In general, problem solving processes involve first and second track officials and non-officials and are therefore not a method employed by grass roots citizen diplomacy groups whose objectives have more to do with relationships.

As citizen groups continue to emerge as viable peacemaking agents, intervening in inter-communal conflicts, the challenge offered by third wave critics is not only to develop practices that are effective in achieving goals, but also to design and develop the goals themselves. These tasks are at once practical and theoretical. They involve creating clearly defined visions of peace as well as the how-to steps for achieving these visions. Rothman (1998), for one, argues for the creative possibilities and opportunities inherent in social conflict. Similarly, Saunders (1999) sees citizens engaged in dialogue over matters of conflict as a hopeful expression of democratic ideals and values. And arguably, it is only through citizen action that democratic ideals - inclusive of the means for constructive, non-violent social change — can be realized (Jenkins, 1993).

The Ignoring of culture, on the other hand, gives rise to a different concern. Avruch, Black and Scimecca (1991) open their book on the topic of conflict and culture with a story told by Meron Benvenisti, a prominent Jewish Israeli who has been a participant in American designed conflict resolution workshops. Expressing frustration with the degree to which conflict appeared to be ignored in his experience, he charges that conflict resolvers treat communal conflicts like a chestboard "where one can think up the best arrangement of chess pieces and move them all at once". Describing an encounter with workshop organizers, he expresses his frustration over the experience: "I wonder if you know who we are at all. For all you care, we can be Zimbabweans, Basques, Arabs, Jews, Catholics, Protestants, Greeks, Turks. To you we are just guinea pigs to be tested, or at best to be engineered". In this extreme, the fear is that conflict transformation practices are overly 'clinical' and the individuals that they are meant to serve have not been considered in their full uniqueness and complexity.

Considering Zartman's argument, Avruch (1998) points out that he is not arguing against culture, but rather "against the relevance of "something that is called"national culture" . Paradoxically, Avruch asserts how Zartman in fact makes a strong argument for the power of culture by asserting the universality of the diplomatic world. Following Zartman's logic, culture indeed matters. However, it is the culture of diplomacy that is the only culture that conflict theorists and practitioners need really be concerned with. John Paul Lederach (1995) points out how culture has often been treated as an aspect of conflict resolutionsomething which, for practitioners is a matter of advanced skill that can be tacked on to knowing the basics of conflict resolution practices. Lederach asks that we see our practices "as a project, a socially constructed, educational phenomenon comprised of purpose, process and content and inherently encompassing culture and ideology". Rather than asking how we need to account for culture in our practices, Lederach turns the question around and asks instead about the cultural assumptions that are embedded in our models (Morgenthau, 1948). 
In other words, the hegemony of western-based conflict resolution practices privileges not only a particular discourse about conflict resolution, but potentially serves to reinforce asymmetries of dominance and control.

Offering another example, Avruch, Black and Scimecca (1991) show how failing to see the cultural basis of our models not only obscures the values and assumptions that are embedded within them, but it also blinds us to the presence and value of alternatives. Kochman's (1981) research on black and white styles of negotiating shows how the privileging of certain concepts of personhood denigrates cultural difference and assigns it to the periphery.

This means that the white theory of negotiation is not simply one theory among a number of alternatives; it becomes theory for negotiation in general. The discourse of such a theory, which, conceptually speaking, is but one folk model among many, gets reified and elevated to the status of - if not science then - an expert system.

In an effort to offer a conceptual framework for understanding the broader scope of peacemaking activities on the part of religious actors, Sampson (1997) turns to writings by Quaker Adam Curle and Mennonite John Paul Lederach, both of whom have reflected upon their peacemaking experiences. A strong priority for justice among religious peacemakers, says Curle, results in a variety of approaches - be they advocacy, mediation or education - the application of which is dependent upon the distribution of power between adversaries. In this regard, Lederach explains how the efforts of religious actors-“for justice's sake" - have gravitated towards activities that seek to empower weak parties and disenfranchised groups. In this regard, advocacy by religious actors has often taken sides on substantive issues in a conflict, with the goal of defending human rights. Furthermore, reconciliation work has often been pursued with the intention to restructure conflict relationships in ways that address systemic injustices, thus building the basis for stable, peaceful relations (Yusif, 1990).

Approaches to social change that include the world within and the world out there are not new. The American peace movement, for instance, likes to quote Ghandi for saying: "You must be the change you wish to see in the world." While at the same time a nonviolent activist deeply committed to transforming the world, his philosophy requires a commitment to the inner development of ahimsa (nonviolence), as an important expression of our human potential (Barash and Webel 2002, 514-518).

Offering another example, the Dalai Lama has experienced decades of engagement with conflict through his tireless non-violent campaign to free Tibet, all the while contending: "Peace in the world thus depends on peace in the hearts of individuals" (Hunt 2002, 56). In the last few decades, an entire body of literature has emerged which explores the linkage between inner peace and world peace. Most notably, a bulk of this literature is grounded in Buddhist perspectives, which, through an emphasis on the interconnectedness of all of life, trace the roots of all violence to the internal states of greed, anger and ignorance that cripples us as individuals. From this view, we transform the world as we transform ourselves through awareness and compassionate involvement (Kraft 1992,12).

At the heart of all of these examples is an assumption that through a commitment to our own growth and development — often by drawing on practices offered through spiritual or so called wisdom traditionswe become better practitioners.

Exploring the question of what the so called "great wisdom traditions" might have to offer to the field of negotiation and conflict resolution is precisely the purpose of a new research and educational forum: The Harvard Negotiation Insight Initiative (HNII). The Insight Initiative forum is part of the Harvard Program on Negotiation's Dispute Resolution Program and was launched "to engage the cutting edge conversation between the fields of negotiation and conflict management on the one hand and those of 
mindfulness and the great wisdom traditions on the other. On October 3, 2003 the Insight Initiative hosted "Beyond Yes," the first evening of its dialogue series. In a high tech lecture hall transformed — ritualizedwith the glow of tea lights placed at every seat, author, scholar and practitioner Bill Ury and author and Rabbi Marc Gafni had a conversation about what the world of spirit might bring to the world of negotiation. According to HNII Director Erica Fox, the starting hunch behind the initiative is that there is something profoundly spiritual about what we do as conflict resolution practitioners. Building on this, Bill Ury expressed his view that "the biggest problem with conflict is right here within ourselves." He went on to express how when it comes to the matter of ourselves, the field of conflict resolution has much to learn from wisdom traditions. From within this full house of those who came to listen and participate that evening, came a questioning of Uri's assumptions. Notably, one young woman asked how, given the degree of injustice, inequality and ongoing violence in the world, can we afford to take time out to work on ourselves. Uri responded without hesitation by saying that we need to do both. While perhaps offering a way through the tension around how to set priorities when doing social transformation work, what I heard in this answer was a reference to the way the field itself appears to be stretching in two, seemingly, opposite directions.

Importantly, just as conversations that seek to include the interior roots of destructive conflict, however this might be defined, are a newly emerging feature of the field, efforts to include ways to address the structural roots of destructive conflict are also relatively new. Illustrative in this regard, are the concerns of those critical of a human relations approach in general, as well as citizen diplomacy efforts and coexistence work in particular. Rothman (1998), for instance, calls a human relations approach "soft and naïve" to the extent that it assumes the issues under contention will disappear once each party sees the 'human face' of the other Lofland (1993) is critical of citizen diplomacy efforts and their tendency to engage in disguised or timid politics. His concern ultimately is that the emphasis on idealism and emotional motifs results in political agendas devoid of substance.

Of concern is how peacemaking interventions in arenas of protracted ethnic conflict may serve to reinforce social and structural asymmetries of dominance and control. In particular, Mohamed Abu-Nimer (1999) is critical of the limited degree to which most dialogue efforts address institutional and structural injustices. Within other areas of the field, the push for more critical, self-reflective practice is also evident.

\section{Conclusion}

In the realm of peacebuilding in divided societies, this push (and pull) in two directions can be found in the nexus of reconciliation, justice and coexistence efforts. Importantly, for those who raise concerns about a human relations approach, the central question is about the degree to which the restoration of relationships - reconciliation - is based on recognizing and amending injustices. Even while critical, Rothman (1998) still contends that a human relations approach may be useful especially at moments of transition from deadlocked, mutually exclusive positions to a more inclusive analysis of the conflict.

Further, Lofland's assumptions lack consideration for the fact that not all forms of political mobilization are constructive. In cases of protracted violent conflict, for instance, adversaries would likely assert that they are engaged in issues of political substance. However, in these cases the results have been an eruption of crisis and a destructive escalation of violence. Importantly, one area where conflict resolution activities have made notable contributions is in situations of de-escalating conflicts (Kriesberg 1998, 223). In this regard, John Paul Lederach (1997) asserts that in order to effectively address inter-communal conflict, efforts often need to shift away from the issues of the conflict and towards a focus on restoring and rebuilding relationships (Gurr, 1993). 
At the heart of this pushing and pulling around the revolutionary and resolutionary features of peacebuilding is what John Paul Lederach (1995) calls "the paradox of justice and mercy". It is here, quite possibly, that the two ends of the field, while appearing to move in opposite directions, may come together. The paradox of justice and mercy has to do with the seeming incompatibility between addressing issues of justice, on the one hand-revolution-and prevalent assumptions about the importance of rebuilding and transforming adversarial relationships - resolution - on the other. Inspired by his Mennonite tradition, Lederach (1997).

Kriesberg (2004) refers to a similar and overlapping set of features, calling them the four dimensions of reconciliation. As he points out, satisfying these different dimensions of peacemaking simultaneously is difficult. In this regard, it may be largely for pragmatic reasons that peacemakers may pursue one dimension of peacemaking, while neglecting another.

In a similar respect this paradox helps to explain the way approaches to conflict transformation are conventionally polarized around approaches that prioritize interior dimensions of peacemaking on the one hand, and exterior dimensions of peacemaking on the other. Yet, my observation is that, practitioners and theorists alike are beginning to think about and approach this paradox in new ways. From the margins of the field, there is arguably a growing consensus that our practices require from us that we learn to hold paradox, both metaphorically and literally speaking. In other words, our practices must be both holistic and selfreflective, recognizing and including the possible depths of human development and the span and complexity of our social worlds.

In this context, that grassroots, citizen efforts, such as the Compassionate Listening Project are also exploring ways to hold these two directions may have further significance. At the genesis of this work was the hunch that this is indeed what they were doing, along with a hunch about the larger significance of this.

\section{References}

Band, A. J. (1991). Popular Fiction and the Shaping of Jewish Identity. In Jewish Identity in America (D. M. Gordis \& B.-H. Yoav, eds.). Los Angele: University of Judaism.

Chang, F. K. (1996). Beijing's reach in the South China Sea. Orbis, 40(3), 353-374. https://doi.org/10.1016/S0030-4387(96)90002-2

Devlin, J. F. (1992). Effects of leadership style on oil policy.

Forsythe, D. P. (2009). The UN and the Arab-Israeli Conflict: What has been Learned in 25 Years? International Organization, 26(04), 705. https://doi.org/10.1017/S002081830000312X

Friedland, R. (2002). Soth 203-5. (November), 1-46.

Gurr, T. D. (1993). Minorities at Risk: A Global View of Ethnopolitical Conflicts. Washington, D.C: Institute of Peace.

Haim, S. (1962). Arab Nationalism. Berkeley: University of California Press.

Jenkins, R. (1993). Rethinking Ethnicity: Arguments and Explorations. London: Sage. Juergensmeyer.

Morgenthau, H. J. (1948). Politics Among Nations. New York: Mc Graw-Hill. 
Quigley, J. (2010). The Statehood of Palestine: International Law in the Middle East Conflict. Cambridge: Cambridge University Press.

Stein, L. (1961). The Balfour Declaration. New York: Simon and Schuster.

Yusif, A. (1990). Hamas: A passing Incident or Permanent Alternative. Chicago: International Center for Research and Studies.

\section{Copyrights}

Copyright for this article is retained by the author(s), with first publication rights granted to the journal.

This is an open-access article distributed under the terms and conditions of the Creative Commons Attribution license (http://creativecommons.org/licenses/by/4.0/). 